\title{
Inhibition of Leukocyte Rolling with Polysaccharide Fucoidin Prevents Pleocytosis in Experimental Meningitis in the Rabbit
}

\author{
Carl Granert, ${ }^{*}$ Johan Raud, ${ }^{\star}$ Xun Xie, ${ }^{\star}$ Lars Lindquist, ${ }^{*}$ and Lennart Lindbom ${ }^{\star}$ \\ ${ }^{*}$ Department of Infectious Diseases, Huddinge Hospital, S-141 86 Huddinge; and ${ }^{\ddagger}$ Department of Physiology and Pharmacology, \\ Karolinska Institutet, S-171 77, Stockholm, Sweden
}

\begin{abstract}
Inflammatory recruitment of leukocytes into the cerebrospinal fluid (CSF) during bacterial meningitis has been shown to contribute significantly to the neurological damage commonly associated with this serious disease. In this study we tested whether or not inhibition of leukocyte rolling, a precondition for firm leukocyte adhesion to vascular endothelium in vivo, may reduce CSF leukocyte recruitment and associated inflammatory changes in rabbits with experimental meningitis. As documented by intravital microscopy of small venules in the rabbit mesentery and tenuissimus muscle, leukocyte rolling was rapidly and profoundly reduced by intravenous treatment with the polysaccharide fucoidin, a homopolymer of sulfated L-fucose known to block the function of the leukocytic "rolling receptor" L-selectin. Moreover, fucoidin treatment dramatically reduced the accumulation of both leukocytes and plasma protein in the CSF of rabbits challenged intrathecally with pneumococcal antigen. These main findings thus illustrate that inhibition of leukocyte rolling, an early and obligatory step in the process of leukocyte extravasation, may be an effective therapeutic approach to attenuate leukocyte-dependent central nervous system damage in bacterial meningitis. (J. Clin. Invest. 1994. 93:929-936.) Key words: blood-brain barrier • cell adhesion • leukocytes $\bullet$ meningitis $\bullet$ microcirculation
\end{abstract}

\section{Introduction}

Bacterial meningitis is characterized by migration of leukocytes and leakage of protein into the subarachnoid space, triggered by local release of inflammatory mediators (1). Apart from being integrated in the host defense, these inflammatory changes, and in particular the accumulation of leukocytes, contribute significantly to the central nervous system (CNS) ${ }^{1}$ injury commonly associated with bacterial meningitis. In fact, there is evidence to indicate that the phagocytic capacity of leukocytes in the cerebrospinal fluid (CSF) is insufficient (24 ), and that the harmful effects of the leukocytes and their

Address correspondence to Dr. Johan Raud, Department of Physiology and Pharmacology, Doktorsringen 6A, 1tr, Karolinska Institutet, S-171 77 Stockholm, Sweden.

Received for publication 11 August 1993 and in revised form 15 November 1993.

1. Abbreviations used in this paper: MPO, myeloperoxidase; CNS, central nervous system; CSF, cerebrospinal fluid; ZAS, zymosan-activated serum.

J. Clin. Invest.

(c) The American Society for Clinical Investigation, Inc.

0021-9738/94/03/0929/08 \$2.00

Volume 93, March 1994, 929-936 cytotoxic products outweigh their beneficial role in this disease (4-7). Accordingly, a number of studies have documented that adjuvant treatment with antiinflammatory agents such as aspirin-like drugs, glucocorticoids, pentoxifylline, and cytokine inhibitors may reduce indices of neurological damage associated with clinical or experimental bacterial meningitis (4, 8-12). Recently, Tuomanen et al. (7) demonstrated that inhibition of leukocyte recruitment to the subarachnoid space by selective interference with the process of leukocyte adhesion very effectively reduced meningeal inflammation in an experimental model of pneumococcal meningitis. Thus, intravenous treatment with a monoclonal antibody directed against the common $\beta$ subunit of the leukocytic CD11/CD18 complex profoundly inhibited both leukocyte and protein accumulation in the CSF and improved the survival rate of the animals. Using the same treatment strategy, Sáez-Llorens et al. (4) obtained similar results in rabbits with experimental Haemophilus influenzae meningitis.

As shown in several intravital microscopic studies of intact microvessels, the leukocyte glycoprotein complex CD11/ CD18 is of critical importance for the process of firm leukocyte adhesion to vascular endothelium of small venules (13-16), a step required for the subsequent diapedesis of leukocytes through the vessel wall. Before this stationary adhesion and the subsequent extravasation, the leukocytes roll along the venular endothelial lining at a much lower velocity than free-flowing blood cells $(13,17-22)$. This dynamic and reversible type of leukocyte binding to the endothelium, not affected by antiCD18 mAbs $(13,14)$, has recently been shown to be dependent on functional expression of leukocytic L-selectin $(19,23$, 24 ), a carbohydrate-binding adhesion receptor belonging to the selectin family (25-28). As first indicated in vitro (29) and directly shown in vivo $(19,20,24)$, retardation of circulating leukocytes by reversible binding to the venular endothelium (i.e., rolling) via selectins is necessary to allow firm leukocyte adhesion to develop at physiological blood flow rates. Consequently, there appears to exist a positive correlation between the extent of leukocyte rolling and the magnitude of subsequent evoked firm adhesion (20). These observations are also in line with previous studies showing that inflammatory leukocyte accumulation in inflamed skin and peritoneum can be markedly reduced by either anti-CD18 or anti-L-selectin mAbs $(13,14,30-33)$.

The polysaccharide fucoidin (a homopolymer of sulfated L-fucose) has been found to block leukocyte rolling in a dosedependent manner without interfering with the process of firm leukocyte adhesion per se, and without lowering the circulating leukocyte count or changing the total leukocyte flux (i.e., rolling and free flowing cells) in microvessels in vivo $(20,34)$. Moreover, several in vitro studies have shown that fucoidin binds to and specifically blocks the adhesive function of L-selectin (34-39). This study was designed to characterize the capacity of this selectin-binding carbohydrate to inhibit CSF 
pleocytosis and the associated meningeal inflammatory changes induced by pneumococcal antigen in the rabbit. To establish the role of leukocyte rolling in this process, the findings in the meningitis model were compared with intravital microscopic observations of leukocyte rolling. Our results demonstrate that fucoidin effectively reduces leukocyte rolling in the rabbit and almost completely inhibits the influx of leukocytes and protein into the subarachnoid space in response to intrathecal administration of heat-killed pneumococci. The findings thus illustrate the potential of inhibiting leukocyte rolling with selectin-binding polysaccharides to reduce leukocytedependent tissue damage in bacterial meningitis.

\section{Methods}

Preparation of pneumococcal antigen. An unencapsulated strain (CSRSCS-2 clone 1) of Streptococcus pneumoniae (Cesam strain, from the Department of Bacteriology, Karolinska Institutet) was cultured overnight on blood agar plates, suspended in pyrogen-free saline, and heat inactivated by boiling for $10 \mathrm{~min}$. The optical density of the final antigen solution was equivalent to a viable count of $10^{6} \mathrm{CFU} / \mathrm{ml}$.

Fucoidin. Fucoidin (F-5631, lot no. 51H3859; Sigma Chemical Co., St. Louis, MO) was dissolved in sterile PBS ( $10 \mathrm{mg} / \mathrm{ml}$ at $\mathrm{pH} 7.3$ ) and passed through a $0.2-\mu \mathrm{m}$ sterile filter before intravenous administration (for dosage, see below). Fucoidin is purified from the brown marine algae Fucus vesiculosus according to Black et al. (40) and is a homopolymer of L-fucose and L-fucose-4-sulfate with a molecular mass between 100 and $150 \mathrm{kD}$. The sulfate content is $2.1 \mathrm{nmol} \mathrm{SO}_{4} / \mu \mathrm{g}$ fucoidin (36).

Experimental meningitis model. A previously described meningitis model in female New Zealand White rabbits $(3.5-4.5 \mathrm{~kg}$ ) was used (41). Briefly, $0.25 \mathrm{ml}$ cerebrospinal fluid was collected from the cisterna magna, whereafter an equal volume of the antigen suspension was injected. Subsequent CSF samples $(0.25 \mathrm{ml})$ were taken after 8 and $24 \mathrm{~h}$. The choice of these time points was based on our previous experience with this antigen, i.e., CSF pleocytosis generally peaks during the first 6-9 $\mathrm{h}$ after antigen challenge, and after $24 \mathrm{~h}$ a substantial number of leukocytes are still present in the CSF (C. Granert, unpublished observation). $10 \mathrm{~min}$ before and $8 \mathrm{~h}$ after antigen inoculation, $1-\mathrm{ml}$ blood samples were drawn from an auricular artery. Fucoidin $(10 \mathrm{mg} /$ $\mathrm{kg}$ ) or an equivalent volume of PBS was administered intravenously at $-5 \mathrm{~min}$, and at 2,4 , and $6 \mathrm{~h}$ relative to the intracisternal introduction of antigen. During each cisternal puncture, the animals were anesthetized with $0.25 \mathrm{ml} / \mathrm{kg}$ i.m. fluanison/fentanyl $(10 / 0.2 \mathrm{mg} / \mathrm{ml}$; Hypnorm Vet; Janssen Pharmaceutica, Beerse, Belgium) and $0.25 \mathrm{ml} / \mathrm{kg}$ i.m. diazepam (Stesolid, $5 \mathrm{mg} / \mathrm{ml}$; Dumex, Copenhagen, Denmark). The experiments were approved by a local ethics committee (applies to all parts of the study described below).

Measurement of circulating leukocyte count and CSF leukocytes, glucose, lactate, and protein. Total and differential leukocyte counts in blood and CSF were carried out in a Bürker chamber after staining. The remaining CSF was centrifuged $(1,200 \mathrm{~g}, 10 \mathrm{~min})$, and the supernatants were stored at $-70^{\circ} \mathrm{C}$ until assayed reflectometrically (Kodak $700 \mathrm{XRc}$ ) for glucose, lactate, and protein using the Kodak Ektachem Clinical Chemistry Slides GLU, LAC, and PROT (Eastman Kodak Company, Rochester, NY).

Intravital microscopic studies of leukocyte rolling. The microcirculatory behavior of leukocytes was directly observed and quantified in the rabbit tenuissimus muscle using a previously described model for intravital microscopy (42). Briefly, male New Zealand White rabbits $(0.8-1.2 \mathrm{~kg}$ ) were sedated with diazepam (Stesolid, $5 \mathrm{mg} / \mathrm{ml} ; 0.25 \mathrm{ml}$ / $\mathrm{kg}$ i.m.) and anesthetized with $20 \%$ urethane $(1.5 \mathrm{~g} / \mathrm{kg}$ i.m.; Sigma Chemical Co.). Spontaneous breathing was facilitated by tracheal cannulation and body temperature was maintained at $38^{\circ} \mathrm{C}$ with the aid of a heating pad and an oesophageal thermistor. Carotid artery and jugu- lar vein catheters were inserted for continuous recording of systemic blood pressure, collection of blood samples, and administration of drugs and additional anesthetic. The intact microcirculation in the exposed tenuissimus muscle, continuously superfused $(2 \mathrm{ml} / \mathrm{min})$ with a Krebs-Henseleit solution (composition [mM]: $\mathrm{KH}_{2} \mathrm{PO}_{4}, 1.2$; $\mathrm{NaHCO}_{3}, 25.0 ; \mathrm{NaCl}, 118.4 ; \mathrm{KCl}, 4.8 ; \mathrm{CaCl}_{2}, 2.5 ;$ and $\mathrm{MgSO}_{4}, 1.19$ ) at $37^{\circ} \mathrm{C}$ equilibrated with $5 \% \mathrm{CO}_{2}$ in $\mathrm{N}_{2}$, was directly observed using an intravital microscope and a salt water immersion lens ( SW 25, NA 0.6; E. Leitz, Inc., Rockleigh, NJ). The microscopic image was recorded on videotape by a Panasonic WV-1550 video camera and a Panasonic AG-6010 video recorder. The leukocyte rolling interaction with the microvascular endothelium was determined from video recordings of small venules (inner diameter, $30-40 \mu \mathrm{m}$ ) in the connective tissue portion of the tenuissimus muscle by counting the number of leukocytes per minute rolling slowly relative to the whole blood flow past a transvascular reference line (rolling leukocyte flux ). After a resting period of 10-15 min, after which basal rolling leukocyte flux was found stable, the animals received a single intravenous injection with fucoidin (10 $\mathrm{mg} / \mathrm{kg}$ ) or PBS. At defined points after treatment, the mean rolling leukocyte flux was calculated from two consecutive 1-min recordings. Changes in the rolling leukocyte flux after fucoidin treatment are presented in percent of the rolling flux before treatment. For micrographs of leukocyte rolling (see Fig. 2), intravital microscopy of the rabbit mesentery was used because of the high resolution obtainable in this tissue. The mesenteric microvasculature of the rabbit was exposed by a midline abdominal incision $(\sim 4 \mathrm{~cm})$ followed by exteriorization of the appendix and terminal ileum. In these experiments, anesthesia, catheters, buffers, etc. were the same as in the studies of the tenuissimus muscle. An automatic microscope camera (Vario Ortomat 2; E. Leitz, Inc.) and Kodak Ectachrome P800/1600 daylight film, exposed at 800 ASA, were used for the micrographs.

Inflammatory skin lesions. Male New Zealand White rabbits (1.5$2.1 \mathrm{~kg}$ ) with their backs shaved $16 \mathrm{~h}$ before the experiments were anesthetized with $0.25 \mathrm{ml} / \mathrm{kg}$ i.m. fluanison/fentanyl $(10 / 0.2 \mathrm{mg} / \mathrm{ml}$; Hypnorm Vet) and $0.25 \mathrm{ml} / \mathrm{kg}$ i.m. diazepam (Stesolid, $5 \mathrm{mg} / \mathrm{ml}$ ). Duplicate intradermal injections $(100 \mu \mathrm{l})$ of PBS and zymosan-activated serum (ZAS) were made at alternate sites in the dorsal region of the animals. Complement activation after a zymosan (Sigma Chemical Co.) concentration in serum of $20 \mathrm{mg} / \mathrm{ml}$, as used in this study, results in $\sim 3 \mu \mathrm{g}$ of $\mathrm{C} 5 \mathrm{a}$ des $\mathrm{Arg} / \mathrm{ml}$ serum (43). The animals were then allowed to recover from the anesthesia and remained in the cages for 4 $\mathrm{h}$ at an ambient temperature of $25^{\circ} \mathrm{C}$. After this period, the animals were killed with an overdose of anesthesia and the skin lesions were carefully removed and dissected free from fat and muscle tissue and weighed. For determination of leukocyte infiltration into the skin lesions, the skin samples were homogenized in $10 \mathrm{ml} 0.5 \%$ hexadecyltrimethylammonium bromide and freeze-thawed, whereafter the myeloperoxidase (MPO) activity of the supernatant was determined. The enzyme MPO is abundant in neutrophil leukocytes (44), and has been found to be a reliable marker for the detection of neutrophil accumulation in inflamed skin areas in vivo (45). The enzyme activity was determined spectrophotometrically as the change in absorbance at 650 $\mathrm{nm}\left(25^{\circ} \mathrm{C}\right)$ that occurs in the redox reaction of $\mathrm{H}_{2} \mathrm{O}_{2}$-tetramethylbenzididne catalyzed by MPO. Values are expressed as MPO U/g tissue. Treatment with fucoidin $(10 \mathrm{mg} / \mathrm{kg}$ i.v.) or an equal volume of PBS was performed $10 \mathrm{~min}$ before and $2 \mathrm{~h}$ after the intradermal injections.

Statistical analysis. Statistical analysis of paired observations was performed using the Wilcoxon signed ranks test, and independent samples were analyzed by the Wilcoxon-Mann-Whitney test.

\section{Results}

Effect of fucoidin on leukocyte rolling. Basal rolling leukocyte flux in small venules of the rabbit tenuissimus muscle at the end of the control period was $48 \pm 17 / \min (\operatorname{mean} \pm \mathrm{SE}, n=5$ ). While intravenous injection of vehicle (PBS) did not affect 


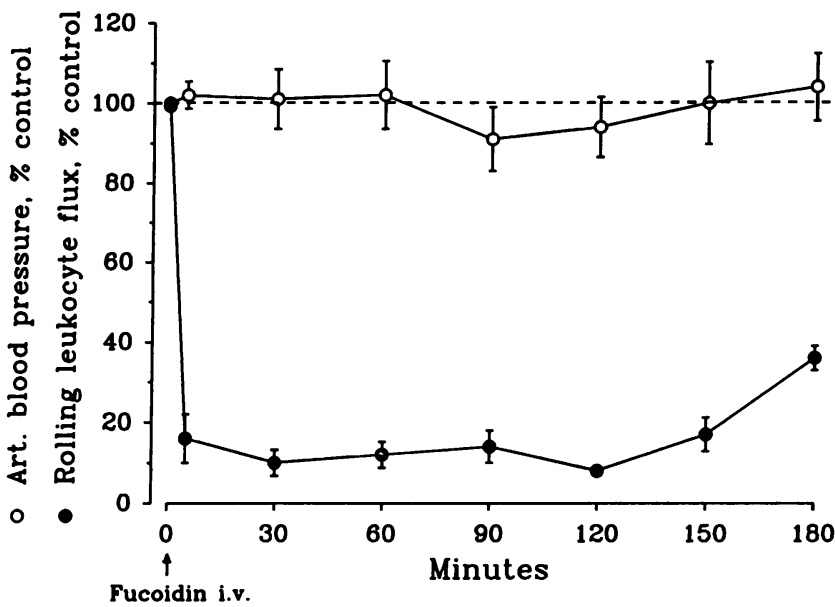

Figure 1. Changes in basal rolling leukocyte flux and arterial blood pressure over time in the rabbit after systemic treatment with fucoidin (in percent of control values before treatment). As observed with intravital microscopy, fucoidin $(10 \mathrm{mg} / \mathrm{kg}$ i.v. at time $0 \mathrm{~h})$ caused a rapid and striking reduction of the number of leukocytes rolling slowly along the endothelium of small venules in the rabbit tenuissimus muscle ( filled circles). This effect was not associated with changes in arterial blood pressure (open circles). Data represent means $\pm \operatorname{SE}(n=5)$.

leukocyte rolling (data not shown), fucoidin administration $(10 \mathrm{mg} / \mathrm{kg})$ resulted in a rapid $\sim 90 \%$ drop in rolling leukocyte flux (Fig. 1). As assessed qualitatively, fucoidin also effectively inhibited leukocyte rolling in the mesenteric microcirculation of the rabbit (Fig. 2). In the tenuissimus muscle, the full effect of fucoidin persisted for $\sim 2 \mathrm{~h}$, whereafter leukocyte rolling gradually increased (Fig. 1). Parallel recordings showed that the effect of fucoidin on rolling could not be attributed to reduced arterial blood pressure (Fig. 1). Moreover, as judged visually, microvascular blood flow remained stable throughout the experiments, and fucoidin treatment did not alter the systemic leukocyte count, i.e., it was $5.92 \pm 0.75 \times 10^{9} /$ liter before treatment, and $6.60 \pm 1.36$ and $7.48 \pm 1.35 \times 10^{9} /$ liter at 30 and $60 \mathrm{~min}$ after treatment, respectively (means $\pm \mathrm{SE}, n=5$ ). If anything, there was a tendency for leukocytosis at $1 \mathrm{~h}$ after fucoidin administration; however, the difference was not statistically significant.

Effect of fucoidin on skin inflammation. In a recent intravital microscopic study in the rat mesentery, we described that graded inhibition of leukocyte rolling with increasing doses of fucoidin results in a proportional reduction of subsequent chemoattractant-induced firm leukocyte adhesion (20). To examine quantitatively whether or not fucoidin, which effectively inhibited leukocyte rolling also in the rabbit (see above), may inhibit inflammatory leukocyte recruitment into an inflamed tissue site, we examined the effect of fucoidin on local accumulation of neutrophils in rabbit skin (measured as MPO activity) after injection of zymosan-activated serum (ZAS, i.e., activated complement factors). In contrast to injection of PBS, intradermal ZAS caused a pronounced accumulation of MPO as measured $4 \mathrm{~h}$ after challenge (Fig. 3). As compared with treatment with vehicle, intravenous fucoidin $(10 \mathrm{mg} / \mathrm{kg})$ given $10 \mathrm{~min}$ before and $2 \mathrm{~h}$ after the intradermal injections resulted in a marked reduction of the ZAS-induced rise in skin MPO
(Fig. 3). Thus, these results strongly suggested that inhibition of leukocyte rolling with fucoidin is indeed an effective method to inhibit leukocyte recruitment into inflamed tissues of the rabbit.

Effect of fucoidin on meningeal inflammation. Intrathecal challenge with pneumococcal antigen resulted in pronounced migration of leukocytes into the subarachnoid space of vehicletreated animals (Fig. 4). This leukocyte accumulation was almost completely inhibited by systemic treatment with fucoidin ( $10 \mathrm{mg} / \mathrm{kg}$, given $5 \mathrm{~min}$ before and at 2,4 , and $6 \mathrm{~h}$ after antigen challenge). Thus, the mean CSF leukocyte count increased from $9 \times 10^{6} /$ liter at $0 \mathrm{~h}$ to $3,096 \times 10^{6} /$ liter $(31 \%$ mononuclear cells) at $8 \mathrm{~h}$ in control animals, and from $6 \times 10^{6} /$ liter at 0 $\mathrm{h}$ to only $15 \times 10^{6} /$ liter at $8 \mathrm{~h}$ in fucoidin-treated animals (Fig. 4). The minor increase in CSF leukocytes after fucoidin treatment was $100 \%$ mononuclear cells in six animals, while two animals showed an increase also in PMNs ( 27 and 50\%, respectively). When the fucoidin treatment was interrupted after $6 \mathrm{~h}$, the leukocytes regained their ability to migrate into the subarachnoid space, as indicated by the mean CSF leukocyte count of $801 \times 10^{6} /$ liter (48\% PMNs) at $24 \mathrm{~h}$ after antigen challenge ( $P<0.05$ vs. values at 0 and $8 \mathrm{~h}$ ) (Fig. 4$)$. In control animals the mean CSF leukocyte count at $24 \mathrm{~h}$ was 1,540 $\times 10^{6} /$ liter (47\% PMNs) (Fig. 4). No adverse effects on the general condition of the rabbits were observed during or after fucoidin treatment.

In the vehicle-treated group, antigen challenge increased the mean CSF protein concentration from $0.43 \mathrm{~g} /$ liter at $0 \mathrm{~h}$ to $1.28 \mathrm{~g} /$ liter $(P<0.01)$ and $1.72 \mathrm{~g} / \operatorname{liter}(P<0.01)$ at 8 and 24 h, respectively (Fig. 5 ). In the fucoidin-treated animals, on the other hand, CSF protein did not increase at $8 \mathrm{~h}$ after antigen challenge, while a moderate elevation $(P<0.05)$ occurred after $24 \mathrm{~h}$ (i.e., $18 \mathrm{~h}$ after the last fucoidin injection) (Fig. 5).

In response to antigen challenge, there was a clear-cut increase $(P<0.01)$ in the mean CSF lactate concentrations at 8 and $24 \mathrm{~h}$ in both vehicle- and fucoidin-treated animals (Fig. 6). However, in the fucoidin-treated group, the mean CSF lactate concentration at $8 \mathrm{~h}$ was significantly reduced in comparison with vehicle treatment, i.e., 5.63 vs. $8.31 \mathrm{mmol} /$ liter, respectively (Fig. 6). At $24 \mathrm{~h}$ there was no longer a difference in CSF lactate concentrations between the two groups (Fig. 6).

Antigen challenge did not significantly change basal CSF glucose levels in either of the two treatment groups as measured at $8 \mathrm{~h}$. Thus, the control glucose levels in the PBS and fucoidin groups were $4.69 \pm 0.18$ and $4.75 \pm 0.21 \mathrm{mmol} /$ liter, respectively, and the corresponding values at $8 \mathrm{~h}$ were $4.01 \pm 0.62$ and $4.64 \pm 0.25 \mathrm{mmol} /$ liter (means $\pm \mathrm{SE}, n=8$ in both groups). At $24 \mathrm{~h}$, a small but significant $(P<0.05)$ reduction in CSF glucose was seen in both vehicle- and fucoidin-treated animals $(3.77 \pm 0.41$ and $3.36 \pm 0.36 \mathrm{mmol} /$ liter, respectively, means $\pm \mathrm{SE}$, $n=8$ in both groups); however, there was no significant difference between the two groups.

As described above, fucoidin did not significantly change the systemic leukocyte count during the first hour after administration (although a tendency towards leukocytosis was observed). However, as compared with vehicle treatment, the leukocyte count was markedly increased after $8 \mathrm{~h}$ of fucoidin administration. Thus, in vehicle-treated rabbits the total leukocyte count was $8.8 \pm 1.2$ at $0 \mathrm{~h}$ and $10.2 \pm 1.1$ at $8 \mathrm{~h}$, while the corresponding values for fucoidin-treated animals were $8.3 \pm 1.0$ at $0 \mathrm{~h}$ and $18.8 \pm 2.5$ at $8 \mathrm{~h}(P<0.01)$. The marked 

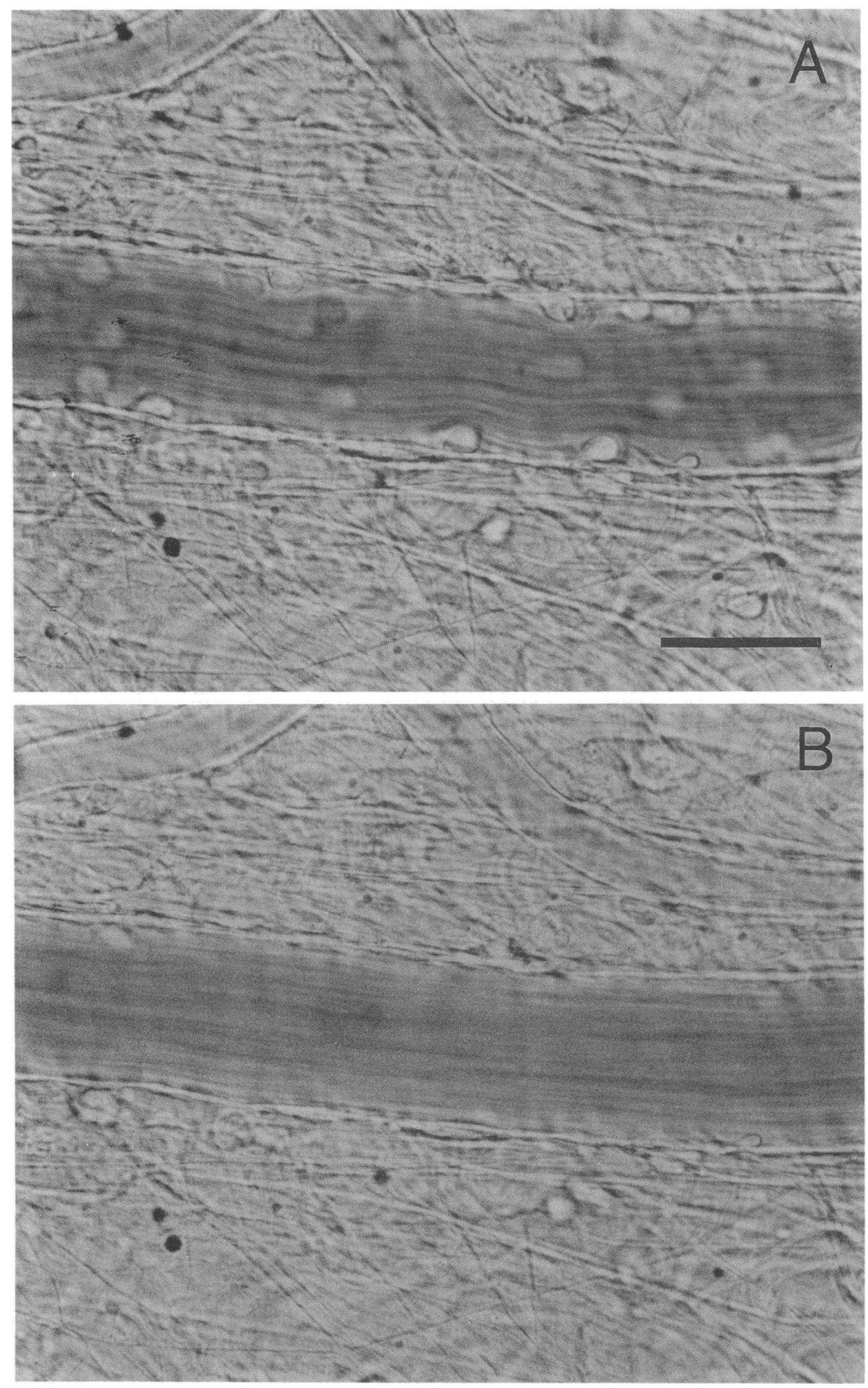

Figure 2. Intravital microscopic images of a rabbit mesenteric venule (direction of blood flow is from left to right ). $(A)$ Basal leukocyte rolling along the venular endothelium; and $(B)$ demonstration that the rolling was abolished 3 min after systemic administration of fucoidin ( 10 $\mathrm{mg} / \mathrm{kg}$ ). Because leukocyte rolling and firm/stationary leukocyte adhesion may look very similar on micrographs, it should be emphasized that, in contrast to rolling leukocytes, firmly adherent leukocytes are not detached by fucoidin treatment. Bar, $40 \mu \mathrm{m}$. leukocytosis after fucoidin treatment was due to an increase in both PMNs ( from $2.2 \pm 0.3$ to $8.6 \pm 1.7, P<0.01$ ) and mononuclear leukocytes (from $6.1 \pm 0.7$ to $10.3 \pm 1.1, P<0.01$ ) ( means \pm SE, $n=7-8$ ).

\section{Discussion}

We have shown that intravenous administration of fucoidin, a homopolymer of sulfated fucose, almost completely inhibited 


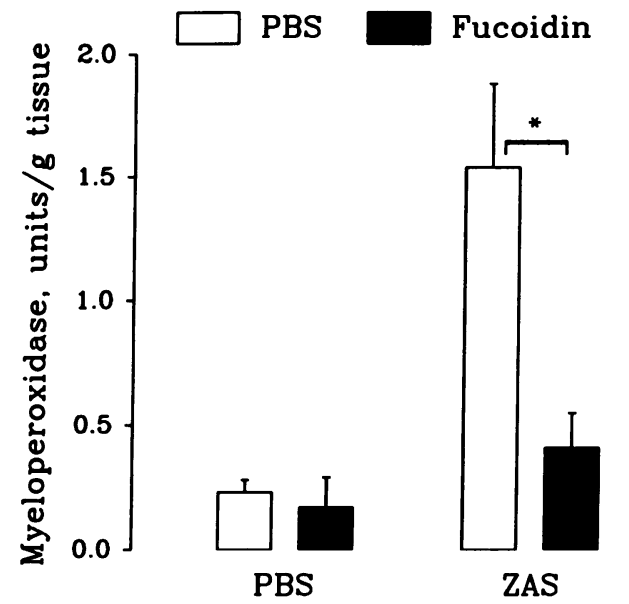

Figure 3. Neutrophil recruitment (indicated by MPO accumulation) into rabbit skin $4 \mathrm{~h}$ after local injection of vehicle (PBS) or activated complement factors in the form of ZAS. Systemic treatment with fucoidin $(10 \mathrm{mg} / \mathrm{kg}$ i.v.) or PBS was performed $10 \mathrm{~min}$ before and 2 $\mathrm{h}$ after the intradermal injections. Data represent means $\pm \operatorname{SE}(n=4$ in each group). ${ }^{*} P<0.05$.

leukocyte and protein accumulation in the CSF of rabbits challenged intrathecally with pneumococcal antigen. By use of intravital microscopy we could also demonstrate that this polysaccharide very effectively inhibited leukocyte rolling in small venules of the rabbit mesentery and tenuissimus muscle. Moreover, fucoidin treatment markedly reduced leukocyte migration into skin lesions, indicating a generalized effect of this carbohydrate on inflammatory leukocyte recruitment.

The reduction in meningeal and skin leukocyte extravasation was evidently a result of interference by fucoidin with leukocyte rolling. This was further supported by the findings

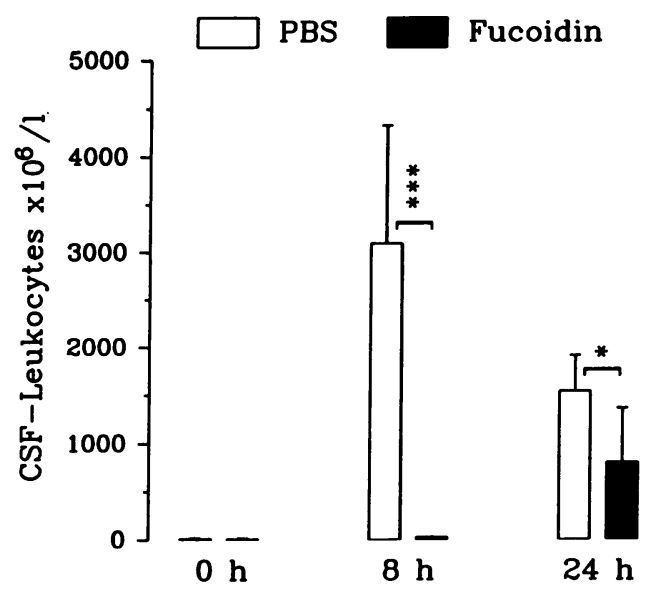

Figure 4. CSF leukocytes over time after intrathecal challenge with pneumococcal antigen in rabbits. Fucoidin $(10 \mathrm{mg} / \mathrm{kg})$ or an equivalent volume of PBS was administered intravenously at $-5 \mathrm{~min}$, and at 2,4 , and $6 \mathrm{~h}$ relative to the intracisternal introduction of antigen at time $0 \mathrm{~h}$. Fucoidin, but not PBS, prevented the leukocyte accumulation at $8 \mathrm{~h}$. Note that the effect of fucoidin on leukocyte rolling was relatively short lasting (see Fig. 1), suggesting that the moderate pleocytosis at $24 \mathrm{~h}$ in fucoidin-treated animals was due to interrupted treatment. Data represent means $\pm \mathrm{SE}(n=8$ in both treatment groups). ${ }^{*} P<0.05 ;{ }^{* * *} P<0.001$.

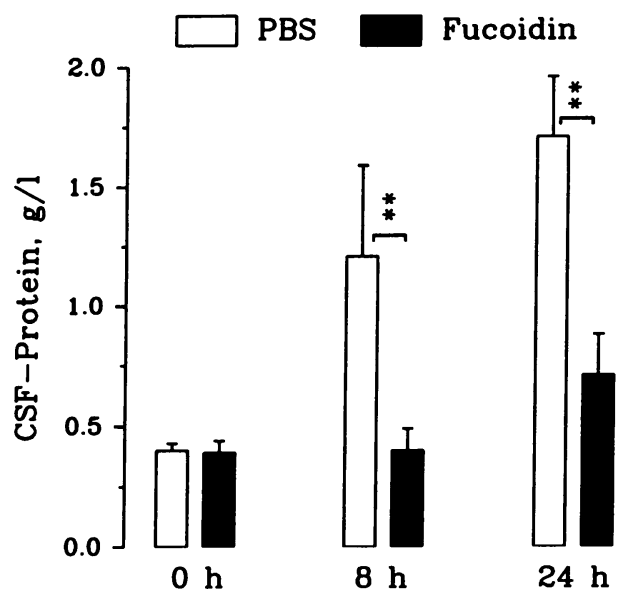

Figure 5. CSF protein over time after intrathecal challenge with pneumococcal antigen in rabbits. Fucoidin $(10 \mathrm{mg} / \mathrm{kg})$ or an equivalent volume of PBS was administered intravenously at $-5 \mathrm{~min}$, and at 2,4 , and $6 \mathrm{~h}$ relative to the intracisternal introduction of antigen at time $0 \mathrm{~h}$. Fucoidin, but not PBS, prevented the increase in CSF protein at $8 \mathrm{~h}$. Regarding the increase in CSF protein from 8 to $24 \mathrm{~h}$ in fucoidin-treated animals, see legend to Fig. 4. Data represent means $\pm \mathrm{SE}$ ( $n=8$ in both treatment groups). ${ }^{* *} P<0.01$.

that the fucoidin-induced inhibition of leukocyte rolling was not associated with a fall in arterial blood pressure or in the number of circulating leukocytes. Moreover, fucoidin has recently been found not to change the degree of leukocyte flux through the microcirculation (although rolling is inhibited) or to block firm leukocyte adhesion per se $(20,34)$. Yet, the exact molecular mechanism by which fucoidin blocked rolling, and consequently adhesion and extravasation of leukocytes (19, 20, 24), cannot be established from this study. However, based on several lines of evidence, the observed effects of fucoidin are most likely related to interference with $\mathrm{L}$-selectin function.

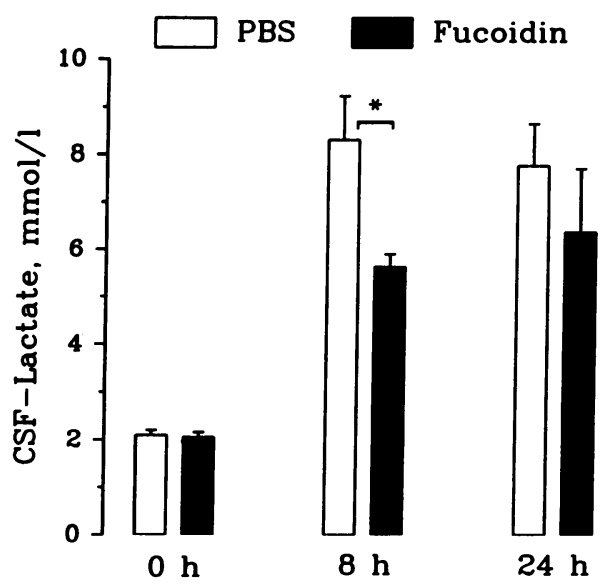

Figure 6. CSF lactate over time after intrathecal challenge with pneumococcal antigen in rabbits. Fucoidin $(10 \mathrm{mg} / \mathrm{kg})$ or an equivalent volume of PBS was administered intravenously at $-5 \mathrm{~min}$, and at 2 , 4 , and $6 \mathrm{~h}$ relative to the intracisternal introduction of antigen at time $0 \mathrm{~h}$. Fucoidin, but not PBS, significantly reduced the increase in $\mathrm{CSF}$ lactate formation at $8 \mathrm{~h}$. Regarding the increase in CSF lactate from 8 to $24 \mathrm{~h}$ in fucoidin-treated animals, see legend to Fig. 4. Data represent means $\pm \operatorname{SE}\left(n=8\right.$ in both treatment groups). ${ }^{*} P<0.05$. 
Namely, fucoidin is known to bind to L-selectin (34-36, 39), and binding of fucoidin to intact leukocytes is inhibited by anti-L-selectin monoclonal antibodies and vice versa $(34,35$, 39). Moreover, fucoidin effectively competes with soluble Lselectin for its ligand on lymph node high endothelial venules $(37,38)$. In addition, the maximal inhibitory effect on leukocyte rolling in vivo appears to be similar $(\sim 80-90 \%)$ for both anti-L-selectin mAbs and fucoidin $(19,20,23,24,34)$.

While it seems reasonable to suggest that fucoidin inhibits rolling by blocking the function of L-selectin, it is not known whether or not fucoidin also interferes with the in vivo function of the induceable endothelial E- and P-selectins, both of which recognize the same or very similar carbohydrate ligands as Lselectin $(27,28,46)$ and promote leukocyte rolling in vitro (29, $47,48)$ as well as in vivo $(49,50)$. If E- and/or P-selectin are involved in the recruitment of leukocytes in the meningitis model, our findings indicate that fucoidin indeed interferes with the function of the endothelial selectins. Such an effect by fucoidin could be mediated either via direct blocking of functional E- and/or P-selectin binding domains, or as an indirect consequence of the suggested reciprocal receptor-ligand relationship between leukocytic L-selectin and the endothelial selectins $(51,52)$. Yet, the purpose of our study was not to specifically analyze the molecular target actions of fucoidin, but to establish in more general terms the therapeutic potential of inhibiting leukocyte rolling with polysaccharides to attenuate leukocyte-dependent CNS injury associated with bacterial meningitis. In this context, fucoidin is clearly a powerful tool.

The deleterious effect of leukocyte recruitment into the subarachnoid space was first indicated by Petersdorf and Luttrell (5), who demonstrated increased survival times in leukopenic dogs with pneumococcal meningitis. More recently, the concept of leukocyte-mediated CNS damage during meningitis has gained substantial support from two studies demonstrating that specific inhibition of stationary leukocyte adhesion by systemic treatment with anti-CD18 mAbs markedly reduced meningitic pleocytosis and indices of neurological injury in rabbits $(4,7)$. In this study, we have shown that inhibition of leukocyte rolling, a precondition for stationary leukocyte adhesion, is at least as effective as anti-CD18 therapy with respect to leukocyte recruitment into the CSF. In fact, knowing that firm leukocyte adhesion may also involve leukocytic molecules other than the CD11/CD18 complex (e.g., $\beta 1$ integrins) (25, 53 ), treatment with compounds that abolish rolling may prove to be sufficient for preventing leukocyte-dependent tissue injury, and possibly even a more effective strategy than treatment with mAbs interfering with single receptors for stationary leukocyte adhesion. In support of receptors for firm leukocyte adhesion other than CD11/CD18 being involved in meningitic pleocytosis, endotoxin-induced meningitis appears to be less sensitive to treatment with anti-CD18 mAbs than experimental meningitis induced by live or heat-killed bacteria ( 4 , 7). Moreover, dexamethasone, which may reduce both meningitic cytokine production as well as the expression of several different adhesion receptors mediating leukocyte-endothelium interactions $(4,54-56)$, has been reported to act additiveley with high doses of anti-CD $18 \mathrm{mAbs}$ in reducing experimental $H$. influenzae-induced pleocytosis (4).

We found that fucoidin more or less completely inhibited the meningitic increase of both leukocytes and protein in the subarachnoid space, indicating that the blood-brain barrier dis- turbance was entirely a result of the leukocyte extravasation. In the meningitis studies in rabbits by Tuomanen et al. (7) and Sáez-Llorens et al. (4), where anti-CD18 mAbs and live bacteria were used, protein leakage into the CSF was reduced by $\sim 50-60 \%$ while pleocytosis was inhibited by $\sim 85-90 \%$. Although this may suggest that fucoidin is somewhat more effective than the mAbs with respect to protein leakage, it is important to point out that, in contrast to fucoidin, treatment of uninfected rabbits with anti-CD18 mAb per se may cause a moderate increase in CSF protein levels for unknown reasons (7). Yet, to be able to make a strict comparison, the effect of fucoidin treatment needs to be tested against challenge with live bacteria as well as different antigens. Nevertheless, the lines of evidence discussed above strongly suggest that leakage of protein into the subarachnoid space during meningeal infection is leukocyte dependent to a major extent. Therefore, therapeutic inhibition of leukocyte adhesion and/or rolling in meningitis may be sufficient to effectively reduce the development of vasogenic brain edema.

The brain edema caused by leukocytes, alone or in concert with inflammatory mediators, may impair cerebral blood perfusion and tissue oxygenation, potentially resulting in local lactic acidosis $(1,57)$. In addition, it has been shown in vitro that leukocyte products can directly induce cerebral lactate production in the absence of hypoxia (58). Further in support of leukocytes contributing to the CSF lactic acidosis seen in meningitis, we found that the peak (at $8 \mathrm{~h}$ ) increase in CSF lactate after antigen challenge was partially inhibited by fucoidin as compared with vehicle treatment. Yet, it is clear that CSF lactic acidosis in meningitis can develop also independent of leukocytes, as indicated by the significant rise in CSF lactate despite almost total absence of pleocytosis after fucoidin treatment. Moreover, in rabbits with pneumococcal meningitis, Ernst et al. (3) reported no difference in CSF lactate concentrations between normal rabbits and leukopenic animals, and others have found no correlation between CSF lactate and the degree of pleocytosis $(6,41)$. In the studies with anti-CD18 mAb treatment, the results on lactate formation are contradictory, i.e., Sáez-Llorens and et al. (4) observed no reduction of CSF lactate levels in rabbits with live $H$. influenzae- or $H$. influen$z a e$ endotoxin-induced meningitis despite substantial inhibition of pleocytosis (4), while Tuomanen (59), in agreement with our findings, has reported reduced lactate formation after anti-CD18 treatment of rabbits with pneumococcal meningitis. Apparently, leukocytes may contribute to some extent to meningitic lactate formation; however, additional studies are necessary to clarify the detailed mechanisms of lactate production in bacterial meningitis.

Fucoidin treatment slowly increased the systemic leukocyte count, which is similar to what has previously been observed in rabbits after treatment with anti-CD18 mAbs $(4,14)$. The mechanism behind this increase in circulating leukocytes after fucoidin (or anti-CD18) treatment is not known. However, given the gradual appearance of the observed leukocytosis (both poly- and mononuclear), one possibility is that inhibition of leukocyte-endothelium interactions prevents the normal elimination of the short-lived PMNs from the circulation, as well as inhibits the homing process of mononuclear cells to peripheral lymphoid tissues. This hypothesis is based on the previous finding that fucoidin may inhibit lymphocyte homing in mice (60), and the assumption that the normal elimination 
of PMNs from the circulation involves similar adhesion pathways as when PMNs are recruited to inflamed tissues, i.e., selectin-mediated rolling and CD11/CD18-dependent firm adhesion.

In summary, we have documented that the sulfated polysaccharide fucoidin effectively inhibits leukocyte rolling in the rabbit and, as a consequence, strikingly reduces pleocytosis and increased CSF levels of plasma proteins evoked by intrathecal challenge with pneumococcal antigen. Our findings clearly illustrate the potential of inhibiting leukocyte rolling with certain polysaccharides as a novel and effective therapeutic approach to reduce leukocyte-dependent CNS damage in bacterial meningitis.

\section{Acknowledgments}

We thank Dr. Lars-Olof Hansson and Roine Hernbrand (Department of Clinical Chemistry, Karolinska Hospital), for analyzing CSF glucose, lactate, and protein.

This study was supported by the Swedish Medical Research Council (14X-4342, 04P-8865, 04P-10738), the Swedish Society of Medicine, the Swedish Society for Medical Research, the Institute of Environmental Medicine, the Lars Hierta, Tore Nilson, and Åke Wiberg Foundations, Upjohn AB, and Karolinska Institutet.

\section{References}

1. Tunkel, A. R., and W. M. Scheld. 1993. Pathogenesis and pathophysiology of bacterial meningitis. Clin. Microbiol. Rev. 6:118-136.

2. Simberkoff, M. S., N. H. Moldover, and J. Rahal, Jr. 1980. Absence of detectable bactericidal and opsonic activities in normal and infected human cerebrospinal fluids. A regional host defense deficiency. J. Lab. Clin. Med. 95:362372.

3. Ernst, J. D., J. M. Decazes, and M. A. Sande. 1983. Experimental pneumococcal meningitis: role of leukocytes in pathogenesis. Infect. Immun. 41:275-279.

4. Sáez-Llorens, X., H. S. Jafari, C. Severien, F. Parras, K. D. Olsen, E. J. Hansen, I. I. Singer, and G. H. McCracken, Jr. 1991. Enhanced attenuation of meningeal inflammation and brain edema by concomitant administration of anti-CD18 monoclonal antibodies and dexamethasone in experimental Haemophilus meningitis. J. Clin. Invest. 88:2003-2011.

5. Petersdorf, R. G., and C. N. Luttrell. 1962. Studies of the pathogenesis of meningitis. I. Intrathecal infection. J. Clin. Invest. 41:311-319.

6. Täuber, M. G., U. Borschberg, and M. A. Sande. 1988. Influence of granulocytes on brain edema, intracranial pressure, and cerebrospinal fluid concentrations of lactate and protein in experimental meningitis. J. Infect. Dis. 157:456464.

7. Tuomanen, E. I., K. Saukkonen, S. Sande, C. Cioffe, and S. D. Wright 1989. Reduction of inflammation, tissue damage, and mortality in bacterial meningitis in rabbits treated with monoclonal antibodies against adhesion-promoting receptors of leukocytes. J. Exp. Med. 170:959-969.

8. Tuomanen, E., B. Hengstler, R. Rich, M. A. Bray, O. Zak, and A. Tomasz. 1987. Nonsteroidal anti-inflammatory agents in the therapy for experimental pneumococcal meningitis. J. Infect. Dis. 155:985-990.

9. Lebel, M. H., B. J. Freij, G. A. Syrogiannopoulos, D. F. Chrane, M. J. Hoyt, S. M. Stewart, B. D. Kennard, K. D. Olsen, and G. H. McCracken, Jr. 1988 Dexamethasone therapy for bacterial meningitis. Results of two double-blind, placebo-controlled trials. N. Engl. J. Med. 319:964-971.

10. Mustafa, M. M., O. Ramilo, K. D. Olsen, P. S. Franklin, E. J. Hansen, B. Beutler, and G. H. McCracken, Jr. 1989. Tumor necrosis factor in mediating experimental Haemophilus influenzae type B meningitis. J. Clin. Invest. 84:1253-1259.

11. Saukkonen, K., S. Sande, C. Cioffe, S. Wolpe, B. Sherry, A. Cerami, and E. Tuomanen. 1990. The role of cytokines in the generation of inflammation and tissue damage in experimental gram-positive meningitis. J. Exp. Med. 171:439448.

12. Odio, C. M., I. Faingezicht, M. Paris, M. Nassar, A. Baltodano, J. Rogers, X. Sáez-Llorens, K. D. Olsen, and G. H. McCracken, Jr. 1991. The beneficial effects of early dexamethasone administration in infants and children with bacterial meningitis. N. Engl. J. Med. 324:1525-1531.

13. Arfors, K.-E., C. Lundberg, L. Lindbom, K. Lundberg, P. G. Beatty, and J. M. Harlan. 1987. A monoclonal antibody to the membrane glycoprotein com- plex CD18 inhibits polymorphonuclear leukocyte accumulation and plasma leakage in vivo. Blood. 69:338-340.

14. Lindbom, L., C. Lundberg, J. Prieto, J. Raud, P. Nortamo, C. G. Gahmberg, and M. Patarroyo. 1990. Rabbit leukocyte adhesion molecules CD11/ CD18 and their participation in acute and delayed inflammatory responses and leukocyte distribution in vivo. Clin. Immunol. Immunopathol. 57:105-119.

15. Argenbright, L. W., L. G. Letts, and R. Rothlein. 1991. Monoclonal antibodies to the leukocyte membrane $\mathrm{CD} 18$ glycoprotein complex and to intercellular adhesion molecule- 1 inhibit leukocyte-endothelial adhesion in rabbits. $J$. Leukocyte Biol. 49:253-257.

16. Perry, M. A., and D. N. Granger. 1991. Role of CD11/CD18 in shear rate-dependent leukocyte-endothelial cell interactions in cat mesenteric venules. J. Clin. Invest. 87:1798-1804.

17. Atherton, A., and G. V. Born. 1972. Quantitative investigations of the adhesiveness of circulating polymorphonuclear leucocytes to blood vessel walls. J. Physiol. (Lond.). 222:447-474.

18. Ley, K., M. Cerrito, and K.-E. Arfors. 1991. Sulfated polysaccharides inhibit leukocyte rolling in rabbit mesentery venules. Am. J. Physiol. 260:H1667H1673.

19. Von Andrian, U. H., J. D. Chambers, L. M. McEvoy, R. F. Bargatze, K.-E. Arfors, and E. C. Butcher. 1991. Two-step model of leukocyte-endothelial cell interaction in inflammation: distinct roles for LECAM- 1 and the leukocyte beta 2 integrins in vivo. Proc. Natl. Acad. Sci. USA. 88:7538-7542.

20. Lindbom, L., X. Xie, J. Raud, and P. Hedqvist. 1992. Chemoattractantinduced firm adhesion of leukocytes to vascular endothelium in vivo is critically dependent on initial leukocyte rolling. Acta Physiol. Scand. 146:415-421.

21. Mayrovitz, H. N. 1992. Leukocyte rolling: a prominent feature of venules in intact skin of anesthetized hairless mice. Am. J. Physiol. 262:H157-H161.

22. Raud, J., and L. Lindbom. 1993. Leukocyte rolling and firm adhesion in the microcirculation. Gastroenterology. 104:310-314.

23. Ley, K., P. Gaehtgens, C. Fennie, M. S. Singer, L. A. Lasky, and S. D. Rosen. 1991. Lectin-like cell adhesion molecule 1 mediates leukocyte rolling in mesenteric venules in vivo. Blood. 77:2553-2555.

24. Von Andrian, U. H., P. Hansell, J. D. Chambers, E. M. Berger, I. Torres Filho, E. C. Butcher, and K.-E. Arfors. 1992. L-selectin function is required for beta 2 -integrin-mediated neutrophil adhesion at physiological shear rates in vivo. Am. J. Physiol. 263:H1034-H1044.

25. Springer, T. A. 1990. Adhesion receptors of the immune system. Nature (Lond.). 346:425-434

26. McEver, R. P. 1991. Selectins: novel receptors that mediate leukocyte adhesion during inflammation. Thromb. Haemostasis. 65:223-228.

27. Lasky, L. A. 1992. Selectins: interpreters of cell-specific carbohydrate information during inflammation. Science (Wash. DC). 258:964-969.

28. Bevilacqua, M. P., and R. M. Nelson. 1993. Selectins. J. Clin. Invest. 91:379-387

29. Lawrence, M. B., and T. A. Springer. 1991. Leukocytes roll on a selectin at physiologic flow rates: distinction from and prerequisite for adhesion through integrins. Cell. 65:859-873.

30. Lewinsohn, D. M., R. F. Bargatze, and E. C. Butcher. 1987. Leukocyte-endothelial cell recognition: evidence of a common molecular mechanism shared by neutrophils, lymphocytes, and other leukocytes. J. Immunol. 138:4313-4321.

31. Price, T. H., P. G. Beatty, and S. R. Corpuz. 1987. In vivo inhibition of neutrophil function in the rabbit using monoclonal antibody to CD18. J. Immunol. 139:4174-4177.

32. Jutila, M. A., L. Rott, E. L. Berg and E. C. Butcher. 1989. Function and regulation of the neutrophil MEL-14 antigen in vivo: comparison with LFAand MAC-1. J. Immunol. 143:3318-3324.

33. Watson, S. R., C. Fennie, and L. A. Lasky. 1991. Neutrophil influx into an inflammatory site inhibited by a soluble homing receptor-IgG chimaera. Nature (Lond.). 349:164-167.

34. Ley, K., G. Linnemann, M. Meinen, L. M. Stoolman, and P. Gaehtgens 1993. Fucoidin, but not yeast polyphosphomannan PPME, inhibits leukocyte rolling in venules of the rat mesentery. Blood. 81:177-185.

35. Yednock, T. A., E. C. Butcher, L. M. Stoolman, and S. D. Rosen. 1987. Receptors involved in lymphocyte homing: relationship between a carbohydratebinding receptor and the MEL-14 antigen. J. Cell Biol. 104:725-731.

36. Imai, Y., D. D. True, M. S. Singer, and S. D. Rosen. 1990. Direct demonstration of the lectin activity of $\mathrm{gp}^{90 \mathrm{MEL}}$, a lymphocyte homing receptor. $J$. Cell Biol. 111:1225-1232.

37. Watson, S. R., Y. Imai, C. Fennie, J. S. Geoffroy, S. D. Rosen, and L. A. Lasky. 1990. A homing receptor-IgG chimera as a probe for adhesive ligands of lymph node high endothelial venules. J. Cell Biol. 110:2221-2229.

38. Imai, Y., M. S. Singer, C. Fennie, L. A. Lasky, and S. D. Rosen. 1991. Identification of a carbohydrate-based endothelial ligand for a lymphocyte homing receptor. J. Cell Biol. 113:1213-1221.

39. Kansas, G. S., O. Spertini, L. M. Stoolman, and T. F. Tedder. 1991 Molecular mapping of functional domains of the leukocyte receptor for endothelium, LAM-1. J. Cell Biol. 114:351-358.

40. Black, W. A. P., E. T. Dewar, and F. N. Woodward. 1952. Manufacture of 
algal chemicals. IV. Laboratory scale isolation of fucoidin from brown marine algae. J. Sci. Food Agric. 3:122-129.

41. Lindquist, L., P. Lundbergh, K.-G. Hedström, L.-O. Hansson, and E. Hultman. 1987. Experimental bacterial meningitis in the rabbit: cerebrospinal fluid changes and its relation to leukocyte response. Scand. J. Infect. Dis. 19:263270.

42. Lindbom, L., R. F. Tuma, and K. E. Arfors. 1982. Blood flow in the rabbit tenuissimus muscle. Influence of preparative procedures for intravital microscopic observation. Acta Physiol. Scand. 114:121-127.

43. Wagner, J. L., and T. E. Hugli. 1984. Radioimmunoassay for anaphylatoxins: a sensitive method for determining complement activation products in biological fluids. Anal. Biochem. 136:75-88.

44. Weiss, S. J. 1989. Tissue destruction by neutrophils. N. Engl. J. Med. 320:365-376.

45. Lundberg, C., and K.-E. Arfors. 1983. Polymorphonuclear leukocyte accumulation in inflammatory dermal sites as measured by $51 \mathrm{Cr}$-labeled cells and myeloperoxidase. Inflammation. 7:247-255.

46. Cummings, R. D., and D. F. Smith. 1992. The selectin family of carbohydrate-binding proteins: structure and importance of carbohydrate ligands for cell adhesion. BioEssays. 14:849-856.

47. Abbassi, O., T. K. Kishimoto, L. V. McIntire, and C. V. Smith. 1993. E-selectin supports neutrophil rolling in vitro under conditions of flow. FASEB (Fed. Am. Soc. Exp. Biol.) J. 7:639a. (Abstr.)

48. McIntire, L. V., D. A. Jones, O. Abbassi, R. P. McEver, and C. W. Smith. 1993. Neutrophil-endothelial adherence under conditions of flow: P-selectin sup ports leukocyte rolling. FASEB (Fed. Am. Soc. Exp. Biol.) J. 7:269a. (Abstr.)

49. Gaboury, J., D. N. Granger, D. C. Anderson, J. Paulson, and P. Kubes. 1993. Superoxide induces leukocyte-endothelial cell interactions by PAF, CD11/ CD18 and P-selectin. FASEB (Fed. Am. Soc. Exp. Biol.) J. 7:270a. (Abstr.)

50. Olofsson, A. M., U. H. Von Andrian, L. Ramezani, B. Wolitzky, and K.-E. Arfors. 1993. E-selectin mediates leukocyte rolling in interleukin-1 treated rabbit mesentery venules. FASEB (Fed. Am. Soc. Exp. Biol.) J. 7:342a. (Abstr.)
51. Kishimoto, T. K., R. A. Warnock, M. A. Jutila, E. C. Butcher, C. Lane, D. C. Anderson, and C. W. Smith. 1991. Antibodies against human neutrophil LECAM-1 (LAM-1/Leu-8/DREG-56 antigen) and endothelial cell ELAM-1 inhibit a common CD18-independent adhesion pathway in vitro. Blood. 78:805811 .

52. Picker, L. J., R. A. Warnock, A. R. Burns, C. M. Doerschuk, E. L. Berg and E. C. Butcher. 1991. The neutrophil selectin LECAM-1 presents carbohydrate ligands to the vascular selectins ELAM-1 and GMP-140. Cell. 66:921-933.

53. Bevilacqua, M. P. 1993. Endothelial-leukocyte adhesion molecules. Annu. Rev. Immunol. 11:767-804.

54. Cronstein, B. N., S. C. Kimmel, R. I. Levin, F. Martiniuk, and G. Weissmann. 1992. A mechanism for the antiinflammatory effects of corticosteroids: the glucocorticoid receptor regulates leukocyte adhesion to endothelial cells and expression of endothelial-leukocyte adhesion molecule 1 and intercellular adhesion molecule 1. Proc. Natl. Acad. Sci. USA. 89:9991-9995.

55. Hartnell, A., A. B. Kay, and A. J. Wardlaw. 1992. Interleukin-3-induced up-regulation of CR3 expression on human eosinophils is inhibited by dexamethasone. Immunology. 77:488-493.

56. Lebel, M. H. 1992. Dexamethasone therapy of bacterial meningitis. In Bacterial Meningitis. H. Schönfeld and H. Helwig, editors. Karger, Basel. 169183

57. Guerra-Romero, L., J. H. Tureen, and M. G. Täuber. 1992. Pathogenesis of central nervous system injury in bacterial meningitis. In Bacterial Meningitis. H. Schönfeld and H. Helwig, editors. Karger, Basel. 18-29.

58. Fishman, R. A., K. Sligar, and R. B. Hake. 1977. Effects of leukocytes on brain metabolism in granulocytic brain edema. Ann. Neurol. 2:89-94.

59. Tuomanen, E. 1992. Adjunctive therapy of experimental meningitis: agents other than steroids. In Bacterial Meningitis. $\mathrm{H}$. Schönfeld and H. Helwig editors. Karger, Basel. 184-191.

60. Spangrude, G. J., B. A. Braaten, and R. A. Daynes. 1984. Molecular mechanisms of lymphocyte extravasation. I. Studies of two selective inhibitors of lymphocyte recirculation. J. Immunol. 132:354-362. 